\title{
Simulation of Potato Late Blight in the Andes. I: Modification and Parameterization of the LATEBLIGHT Model
}

\author{
Jorge L. Andrade-Piedra, Robert J. Hijmans, Gregory A. Forbes, William E. Fry, and Rebecca J. Nelson
}

First author: International Potato Center (CIP), P.O. Box 1721 1977, Quito, Ecuador; second, third, and fifth authors: International Potato Center (CIP), P.O. Box 1558, Lima 12, Peru; and fourth author: Department of Plant Pathology, 334 Plant Sciences Building, Cornell University, Ithaca, NY 14853.

Current address of R. J. Hijmans: Museum of Vertebrate Zoology, University of California, 3101 Valley Life Sciences Building, Berkeley 94720.

Current address of R. J. Nelson: Department of Plant Pathology, 322 Plant Science, Cornell University, Ithaca, NY 14853.

Accepted for publication 16 June 2005.

\begin{abstract}
Andrade-Piedra, J. L., Hijmans, R. J., Forbes, G. A., Fry, W. E., and Nelson, R. J. 2005. Simulation of potato late blight in the Andes. I: Modification and parameterization of the LATEBLIGHT model. Phytopathology 95:1191-1199.

LATEBLIGHT, a mathematical model that simulates the effects of weather, host growth and resistance, and fungicide use on asexual devel-

for the effect of temperature on lesion growth rate (LGR) and sporulation rate (SR); (ii) the incorporation of temperature-dependent latent period (LP); and (iii) the use of experimentally measured parameters of LGR, SR, and LP for specific potato cultivars and pathogen lineages. The model was parameterized for three Peruvian potato cultivars (Tomasa, Yungay, and Amarilis) infected with isolates of a new clonal lineage of P. infestans that is currently predominant in Ecuador and Peru (EC-1).
\end{abstract} opment and growth of Phytophthora infestans on potato foliage, was modified so that it can be used in the Andes and, eventually, worldwide. The modifications included (i) the incorporation of improved equations
Additional keywords: fitness components, tropical highlands.
Potato is an important global food crop that is increasingly produced in developing countries (84). Late blight disease, caused by the oomycete Phytophthora infestans (Mont.) de Bary, is one of the main production constraints of the crop (28). The Andes and other tropical highlands, i.e., zones within $23.5^{\circ}$ of the equator and at altitudes above $1,000 \mathrm{~m}(38,40)$, are among the areas where the disease can be very severe (41), especially among resourcepoor farmers with limited access to disease management options $(38,58)$. Farmers in the tropical highlands control late blight through disease escape, i.e., growing the crop partly outside of the rainy season when the environment is less favorable for late blight, but also less favorable for plant growth $(13,39,62)$, or at high-altitude locations where low temperature restricts the growth of the pathogen (18). These disease escape practices may result in yield losses due to water stress and frost that could be as high as those that would have otherwise been caused by late blight (13, 18,62). Farmers also apply fungicides (18) and can plant resistant cultivars (22), but resistance levels of available cultivars are rarely sufficient, and many of the most popular cultivars are highly susceptible to late blight.

Resistant potato cultivars require less fungicide (24). However, determining the optimal number and timing of fungicide applications for a specific location is a difficult task that demands extensive field experimentation. This is particularly problematic in the Andes and other tropical highland areas where there is large variation among locations in weather, cultivars, and socio-economic conditions $(9,61)$. Under such circumstances, computer-based simulation models may be an effective tool to assist in developing control strategies for specific locations, seasons, cultivars, and

Corresponding author: J. L. Andrade-Piedra; E-mail address: j.andrade@ cgiar.org

DOI: 10.1094/PHYTO-95-1191

(C) 2005 The American Phytopathological Society pathogen populations. This approach can reduce costs because only the most promising strategies need to be evaluated in the field (70,71). Among the many simulation models for potato late blight $(4,19,48,52,53,69,77,80,81)$, the one developed by Bruhn and Fry (4) (hereafter referred to as LATEBLIGHT [3]) is probably the most extensively used to investigate disease management practices $(14,15,20,25,44,54,65,70-74)$.

In the most recent version of LATEBLIGHT (hereafter referred to as LB1990), the asexual life cycle of $P$. infestans is modeled deterministically with four fitness components (sensu Antonovics and Alexander [2]): lesion growth rate (LGR), sporulation rate (SR), latent period (LP), and infection efficiency (IE). Each component has parameters dependent on pathogen and host genotypes. The pathogen parameters are constants that describe the maximum aggressiveness of a particular $P$. infestans genotype, i.e., the values of the fitness components on a completely susceptible cultivar under optimal environmental conditions. The host parameters are multiplication factors that define three general categories of host resistance: susceptible, moderately resistant, and resistant. For each fitness component, the product of host and pathogen parameters defines the interaction, i.e., the growth and development of $P$. infestans on a potato cultivar under optimal environmental conditions. Each resulting value, with the important exception of LP, is further multiplied by factors obtained from equations that describe the effect of weather variables on the host-pathogen interaction. The simulation is carried out using a daily time step. Further details of the model are described elsewhere $(3,4,15,27)$.

LATEBLIGHT was developed, validated, and used for conditions near Ithaca, NY. There are a number of limitations that need to be resolved before LATEBLIGHT can be used for other locations. First, several key parameters are out of range of experimentally observed values and, therefore, are biologically meaningless. These parameters were estimated by calibration $(15,27)$, i.e., 
by adjusting their values until the output of the model gave a good fit to disease severity observed in the field (68). The main inconsistency for pathogen parameters is for LP. The LB1990 version uses an LP value of 6 days (27), while observed LP varies between 2.46 and 4.10 days when measured on a susceptible potato cultivar under optimal environmental conditions $(6,36$, 37,44). For host parameters, there are inconsistencies with LGR and SR. For LGR, the host parameters (multiplication factors) are $1.5,1.4$, and 1.4 , and for SR are $0.55,0.45$, and 0.45 , for the susceptible, moderately resistant, and resistant categories, respectively (27). In the case of LGR, the host parameters are higher than 1 and, therefore, illogical because, when multiplied by the pathogen parameter, they generate values for the host-pathogen interaction 40 to $50 \%$ higher than the maximum value defined by the pathogen parameter. In the case of SR, the host parameters for the moderately resistant and resistant categories are within the range of experimentally observed data, but the value for the susceptible category is again illogical because the resulting value for the interaction is $55 \%$ of the maximum defined by the pathogen parameter.

Despite all these inadequacies, the model has been successfully used to develop general strategies of fungicide utilization. Biologically meaningless parameters were apparently not an obstacle because only general categories of resistance for the host and a single population for the pathogen were usually considered (14, 65,70-73), and because the use of the model for research purposes has been restricted to the region for which it was originally calibrated (Ithaca, NY). Rykiel (68) mentions that the output of a model may be valid even though parts of it are scientifically invalid. In contrast, we intend to use the model to develop not only general strategies for fungicide utilization, but also cultivarand lineage-specific strategies, and as an educational tool for teaching epidemiological concepts. We also intend to use the model for highly diverse environmental conditions, and biologically realistic parameters should increase the likelihood of obtaining a model that is valid across diverse environments.

An additional reason to reassess fitness components is that some of the original parameters used in LATEBLIGHT represent a pathogen population that has been displaced by new, more aggressive populations. The pathogen parameters for LGR and SR were obtained from data reported by Guzmán-N (36) and Lapwood (46) in the early 1960s, when presumably the US-1 clonal lineage (sensu Goodwin et al. [30]) or "old" population (sensu Spielman et al. [75]) was dominant worldwide (31). Starting in the late 1970s, "new" populations of P. infestans that migrated out of Mexico replaced the old population in many regions of the world (26), including the Andes $(21,64)$. Isolates belonging to the new populations of $P$. infestans from the United States and the United Kingdom are more aggressive on potato foliage than those of the old population $(6,12,44,55,56)$, but there are no reports demonstrating that Andean pathogen populations have become more aggressive. However, the increasing importance of late blight in this region $(17,57,62)$ suggests that this is the case.

In addition to inconsistent parameters, LATEBLIGHT also has a significant structural limitation: LP is assumed to be constant at all temperatures $(4,27)$, while experimental data indicate that LP is highly dependent on temperature (37). Moreover, the equations that describe the effect of temperature on LGR and SR were derived from data reported in 1934 by Crosier (11), who presumably worked with isolates belonging to the US-1 clonal lineage, and it is not clear whether isolates of the new populations of the pathogen will have the same response to temperature as do isolates of the old population. Adding an equation for the effect of temperature on LP, and improving those for LGR and SR should make the model more accurate in areas with large variability in temperature.

In this paper, we describe experimental results that were used to modify LATEBLIGHT to accommodate the limitations mentioned above, so that the model can be used to simulate the disease in the Andes and, eventually, worldwide. First, we revised the equations for the effect of temperature on LGR and SR, and derived a new equation for the effect of temperature on LP. Second, we parameterized the model, specifically LGR, SR, and LP, using a sample of potato cultivars and $P$. infestans isolates from Peru. For both calculation of the equations and parameterization, the approach was to estimate fitness components in singlegeneration experiments carried out under controlled conditions according to the "predicted fitness" methodology described by Antonovics and Alexander (2).

\section{MATERIALS AND METHODS}

Growth chamber experiments. Two experiments were conducted in 1998. The first "temperature experiment" was designed to develop equations that describe the effect of temperature on LGR, SR, and LP, and was done at Cornell University, Ithaca, NY. The second "parameterization experiment" was designed to estimate LGR, SR, and LP in a sample of $P$. infestans and potato cultivars from Peru and was conducted at the International Potato Center (CIP) in Lima, Peru.

Isolates. For both experiments, isolates of $P$. infestans collected in the highlands of Peru and maintained in CIP's culture collection were used. For the parameterization experiment, four isolates (PCZ94, PCZ95, PCZ108, and PCZ144) collected in February 1997 near the town of Amparaes (2,735 to 3,010 m above sea level) in the department of Cusco were used. For the temperature experiment, eight isolates were used: four (PCO41, PCO43, PCO47, and PCO48) collected in April 1998 near the town of Comas $(2,400 \mathrm{~m}$ above sea level) in the department of Junín, and four (POX35, POX36, POX41, and POX42) collected also in April 1998 near the town of Oxapampa (1,800 m above sea level) in the department of Pasco. Pathogen isolation, culture, and storage were as described by Pérez et al. (64). The isolates were characterized for metalaxyl sensitivity $(21,78)$, mating type $(64$, 76), and restriction fragment length polymorphism (RFLP) with the RG57 probe $(32,64)$. All the isolates belonged to the EC-1 clonal lineage (sensu Forbes et al. [21]) based on their characteristic features: resistance to metalaxyl, A1 mating type, and particular RFLP fingerprint. This clonal lineage belongs to the new populations of $P$. infestans and is widely distributed in Ecuador (21) and Peru (64).

Quarantine precautions. For the temperature experiment, Peruvian isolates were carried from Peru under a permit from the National Institute of National Resources (INRENA, Instituto Nacional de Recursos Naturales) and into the United States under a permit from the Animal and Plant Health Inspection Service of the U.S. Department of Agriculture. At Cornell, the isolates were transferred to fresh rye B agar in a laminar-flow biosafety cabinet. At the end of the experiment, all materials were autoclaved before disposal. Other precautions were similar to those described by Tooley et al. (79).

Potato cultivars. For the temperature experiment, cv. Superior (susceptible to late blight) from the United States was used. The plants were grown in a greenhouse with temperatures ranging from 18 to $25^{\circ} \mathrm{C}$ and 14-h day photoperiod using Lucalox $400 \mathrm{~W}$ GE lamps (General Electric Co., Schenectady, NY) from October to December. For the parameterization experiment, three Peruvian cultivars were used: 'Tomasa Tito Condemayta' (hereafter referred to as 'Tomasa') (CIP 720072), 'Yungay' (CIP 720064), and 'Amarilis-INIA' (hereafter referred to as 'Amarilis') (CIP 384866.5). The reactions of these cultivars to P. infestans have been reported as highly susceptible, tolerant (moderately resistant), and resistant, respectively (23). The plants were grown in a net house with temperatures ranging from 14 to $24^{\circ} \mathrm{C}$ and no supplemental light from August to October.

Inoculum production. Sporangia for inoculum were produced on leaflets of cv. Superior (temperature experiment) or cv. Tomasa 
(parameterization experiment). Nonterminal leaflets were harvested randomly from the fourth or fifth fully expanded leaves (47) of 6- to 8-week-old plants (56) and were placed abaxial side up in 15-cm-diameter petri plate moist chambers (79). Each leaflet was inoculated by placing a $0.5-\mathrm{cm}$-diameter piece of a 10- to 14-day-old $P$. infestans colony grown on rye B agar on the midrib, covered with a drop of distilled water. The petri plates were sealed with Parafilm and incubated in a growth chamber with constant temperature of $18^{\circ} \mathrm{C}\left( \pm 1^{\circ} \mathrm{C}\right)$, weak light $\left(0.5 \mu \mathrm{E} \mathrm{m}^{-2} \mathrm{~s}^{-1}\right)$, and 14-h day photoperiod $(44,79)$. Five leaflets were inoculated with each isolate. Sporangia were collected in water from 6-dayold lesions (56). The two experiments were conducted in two locations (Lima and Ithaca) with different potato cultivars grown under different conditions. Therefore, inoculum concentration was adjusted for each experiment to provide measurable lesions. These concentrations were $1.5 \times 10^{4}$ (temperature experiment) and $0.5 \times 10^{4}$ sporangia $\mathrm{ml}^{-1}$ (parameterization experiment) as determined from at least two hemacytometer readings per isolate. The sporangia suspensions were kept at $4^{\circ} \mathrm{C}$ for $40 \mathrm{~min}$ to promote release of zoospores.

Inoculation and incubation. Detached leaflets of the appropriate cultivar were inoculated in petri plate moist chambers (described previously). Each leaflet was inoculated by placing a $50-\mu l$ drop of the sporangia/zoospore suspension on the midrib (56). One petri plate containing three leaflets was used for each treatment in each replication of the experiments.

In the temperature experiment, the leaflets were incubated initially at $18^{\circ} \mathrm{C}\left( \pm 1^{\circ} \mathrm{C}\right)$ with no light for $12 \mathrm{~h}$ to assure infection. Subsequently, the leaflets were incubated at 8, 13, 18, 23, and $28^{\circ} \mathrm{C}\left( \pm 1^{\circ} \mathrm{C}\right)$, intense light $\left(150 \mu \mathrm{E} \mathrm{m}^{-2} \mathrm{~s}^{-1}\right)$, and 14-h day photoperiod. In the parameterization experiment, the incubation conditions were the same as those used for inoculum production.

Measurements. Incubation period (IP), LP, lesion area (LA), and sporulation (SP) were measured in each leaflet. IP (hours) and LP (hours) were evaluated every $6 \mathrm{~h}$ starting $24 \mathrm{~h}$ after inoculation (HAI) and finishing at $210 \mathrm{HAI}$ (temperature experiment) or $138 \mathrm{HAI}$ (parameterization experiment) using a dissecting microscope $(\times 10)(44,56)$. IP was defined as the time after inoculation when necrotic spots appeared, and LP as the time after inoculation when sporangia appeared.

Each lesion was photographed digitally at 144 HAI in both experiments. At that time, the lesions had not yet reached the margin of the leaflets. LA (square meters), including the sporulating annulus (46), was measured using ImageTool (University of Texas Health Science Center, San Antonio, TX) (temperature experiment) (56) or SigmaScan Pro software (Jandel Corporation, San Rafael, CA) (parameterization experiment). These values were used in calculating lesion growth rate (LGR, meters per day). It was assumed that the lesions (i) grew in a circular fashion and (ii) had a constant radial growth rate after the IP (29). The radius of each lesion was calculated, and then it was divided by the period between the time of evaluation and IP, according to equation 1:

$$
\mathrm{LGR}=\frac{\sqrt{\mathrm{LA} / \pi}}{144-\mathrm{IP}} \times 24
$$

SP, or the total sporangial load at the time of evaluation, was evaluated at $145 \mathrm{HAI}$ in both experiments following the method described by Mizubuti and Fry (56). Each lesion, including the sporulating annulus, was removed from the leaflet and transferred to a $15-\mathrm{ml}$ vial containing $2.5 \mathrm{ml}$ of distilled water and $2.5 \mathrm{ml}$ of preservative solution $(0.04 \mathrm{M}$ copper sulfate, $0.2 \mathrm{M}$ sodium acetate, acetic acid, $\mathrm{pH}$ 5.4) (75). Each vial was agitated in a vortex for $10 \mathrm{~s}$, and the leaf tissue was removed. The vials were stored at $4{ }^{\circ} \mathrm{C}$ for up to 1 week. An estimate of the concentration of $P$. infestans sporangia (sporangia per milliliter) was obtained using a hemacytometer with at least two readings per vial. Values of SP were calculated by multiplying the sporangia concentration by the volume of preservative solution. To calculate SR (sporangia per square meter per day), it was assumed that (i) sporulation occurs on an annulus that surrounds a nonsporulating initial necrotic area (46); (ii) the radial growth rate of the sporulating annulus is constant and equal to LGR; and (iii) the infectious period (63) of sporulating tissue is 1 day. The sensitivity of model predictions to deviations from these and other assumptions has not been defined. SR rate was calculated with equation 2:

$$
\mathrm{SR}=\mathrm{SP} / \mathrm{SA}
$$

where SA is sporulating area (square meters), i.e., the difference between LA and the area before LP. SA was calculated with equation 3:

$$
\mathrm{SA}=\mathrm{LA}-\left[\pi \times\left(\frac{\mathrm{LP}-\mathrm{IP}}{24} \times \mathrm{LGR}\right)^{2}\right]
$$

In the temperature experiment, LGR, SR, and LP were expressed as proportions relative to maximum (for LGR and SR) or minimum (for LP) values specific to this experiment. The maximum values were obtained with cubic polynomial regressions of LGR or SR on temperature, while the minimum value was obtained with a quadratic polynomial regression of LP on temperature. The proportions obtained in this way were referred to as relative LGR (rLGR), relative SR (rSR), and relative LP (rLP) and represented the effect of temperature on the fitness components.

Data from other studies on LGR and LP were also transformed into relative values in order to make comparisons with data from this study. For LGR, two sets of data were used for such comparisons: first, data reported by Crosier (Fig. 11 in literature citation 11 [page 26]) on the relationship of temperature to progression of stem lesions; and second, data reported by Mizubuti and Fry (Fig. 3B in literature citation 56 [page 841]) on the effect of temperature on LA, which were transformed into LGR using equation 1. For LP, comparisons were made with data reported by Hartill et al. (Fig. 2 in literature citation 37 [page 182]) on the relationship of temperature and LP on potato foliage.

Data analysis. Each experiment was conducted three times, each one on a different date. Each observation was the mean of three subsamples (leaflets), and each date was considered a block in the analysis.

In the temperature experiment, the effects of temperature, isolate, and temperature-isolate interaction on rLGR, rSR, and rLP were tested with analysis of variance. The linear model was $Y_{i j k}=$ $\mu+\rho_{i}+\alpha_{j}+\beta_{k}+\alpha \beta_{j k}+\varepsilon_{i j k}$, where $\mu$ is the overall mean; $\rho_{i}$ is the random effect of the $i$ th block; $\alpha_{j}$ is the fixed effect of the $j$ th temperature; $\beta_{k}$ is the random effect of the $k$ th isolate; $\alpha \beta_{j k}$ is the effect of the interaction between the $j$ th temperature and the $k$ th isolate; and $\varepsilon_{i j k}$ is the random experimental error in the $i j k$ th observation. The sum of squares of temperature was partitioned into orthogonal polynomial contrasts to determine the best-fitting polynomial regressions (45). Coefficients of multiple determination $\left(R^{2}\right)$ were calculated to estimate the variability explained by the regression equations (60). Predicted values of rLGR, rSR, and rLP equal to one indicated that the temperature was optimal for the fitness components.

In the parameterization experiment, the effects of cultivar, isolate, and cultivar-isolate interaction on LGR, SR, and LP were tested with analysis of variance with the same linear model used for the temperature experiment, with the exception that $\alpha_{j}$ was considered the fixed effect of the $j$ th cultivar, and $\alpha \beta_{j k}$ was the effect of the interaction between the jth cultivar and the $k$ th isolate. The Tukey's test $(\alpha=0.05)$ was used for comparing cultivar means (45).

Assumptions of normal distribution and homogeneous variance of experimental errors in both experiments were tested as described by Neter et al. (60). All the analyses were done using SAS 
software, release 8.02 (Statistical Analysis Systems, SAS Institute Inc., Cary, NC).

In order to obtain the parameters for the host-pathogen interaction, the means of LGR, SR, and LP for each cultivar obtained in the parameterization experiment were adjusted to the optimal temperature using the corresponding equation obtained in the temperature experiment. This was done because the parameters for the host-pathogen interaction represent the maximum growth and development of a $P$. infestans genotype on a potato cultivar under optimal environmental conditions, and the incubation temperature in the parameterization experiment was different from the optimal temperature for LGR, SR, and LP. For example, LGR of cv. Tomasa was $3.63 \times 10^{-3} \mathrm{~m} \mathrm{day}^{-1}$ at $18^{\circ} \mathrm{C}$ (incubation temperature in the parameterization experiment). Using the corresponding equation of Table 1 , it was adjusted to $4.10 \times 10^{-3} \mathrm{~m}$ day $^{-1}$ (Table 2) that represented the maximum LGR value (i.e., at the optimal temperature of $22.5^{\circ} \mathrm{C}$, described below).

Versions of LATEBLIGHT. The LB1990 version $(15,27)$ was used as the starting version in this study. This version was based on the original model $(3,4)$ and was first translated from $\mathrm{C}$ language into SAS language and then modified as described below obtaining the current version of the model, hereafter referred to as LB2004. The LB1990 and LB2004 versions are available upon request from the corresponding author or from the Global Initiative on Late Blight website (GILB, available online from CIP).

\section{RESULTS}

Temperature experiment. The interactions between temperatures and isolates were not statistically significant for $\operatorname{rLGR}(P=$ $0.250), \mathrm{rSR}(P=0.720)$, and $\operatorname{rLP}(P=0.997)$. Therefore, it was possible to analyze the effects of temperature and isolates on rLGR, rSR, and rLP as additive. There were significant differences among isolates for $\operatorname{rLP}(P=0.020)$, but there were no differences among them for $\operatorname{rLGR}(P=0.165)$ and $\operatorname{rSR}(P=0.177)$. As expected, the effect of temperature was highly significant for rLGR, rSR, and rLP $(P<0.001)$. The quartic (fourth order) term of the polynomial regressions of rLGR and rSR on temperature was not significant $(P>0.050)$, but the cubic, quadratic and linear terms were highly significant $(P<0.001)$. Therefore, cubic polynomial regressions were selected to describe the effect of temperature on rLGR and rSR (Table 1). For rLP, the quartic and cubic terms were not significant $(P>0.050)$, while the quadratic and linear terms were highly significant $(P<0.001)$ and, therefore, a quadratic polynomial regression was selected to describe the effect of temperature (Table 1). The regressions explained
84.7, 60.7, and $90.3 \%$ of the observed variability of rLGR, rSR, and rLP, respectively (Table 1). These equations are referred to as the "LB2004 equations" in contrast to the "LB1990 equations" used in the LB1990 version of the model.

The effect of temperature on LGR was described in a similar manner by the LB1990 and the LB2004 equations at temperatures above $18^{\circ} \mathrm{C}$, but major differences were found below this temperature (Fig. 1A). The optimal temperature was $21.7^{\circ} \mathrm{C}$ according to the $\mathrm{LB} 1990$ equation and $22.5^{\circ} \mathrm{C}$ according to the $\mathrm{LB} 2004$ equation. At temperatures below the optimal, especially below $18^{\circ} \mathrm{C}$, the LB1990 equation predicted higher lesion growth rates than those predicted by the LB2004 equation. Data from Crosier (11) and Mizubuti and Fry (56) were generally closer to the LB2004 equation than to the LB1990 equation, with one notable exception of rLGR at $10^{\circ} \mathrm{C}$ calculated from Mizubuti and Fry. The data from Crosier had an outlier at $25^{\circ} \mathrm{C}$ (Fig. 1A).

The effect of temperature on SR was described differently by the LB2004 equation compared with the LB1990 equation

TABLE 2. Ranked means, standard deviations (SD), and adjusted means of lesion growth rate (LGR), sporulation rate (SR), and latent period (LP) of three Peruvian potato cultivars inoculated with isolates of the EC-1 clonal lineage of Phytophthora infestans ${ }^{\mathrm{a}}$

\begin{tabular}{llcccc}
\hline $\begin{array}{l}\text { Fitness } \\
\text { component }^{\mathrm{b}}\end{array}$ & Cultivar & $\begin{array}{c}\text { Reaction to } \\
\text { P. infestans }^{\mathrm{c}}\end{array}$ & Mean $^{\mathrm{d}}$ & SD & $\begin{array}{c}\text { Adjusted } \\
\text { mean }^{\mathrm{e}}\end{array}$ \\
\hline LGR $\left(\times 10^{-3}\right)$ & Tomasa & $\mathrm{S}$ & $3.63 \mathrm{a}$ & 0.30 & 4.10 \\
& Yungay & MR & $3.24 \mathrm{~b}$ & 0.26 & 3.66 \\
& Amarilis & $\mathrm{R}$ & $3.01 \mathrm{~b}$ & 0.50 & 3.40 \\
$\mathrm{SR}\left(\times 10^{8}\right)$ & Tomasa & $\mathrm{S}$ & $2.15 \mathrm{a}$ & 0.90 & 2.92 \\
& Yungay & MR & $1.90 \mathrm{a}$ & 0.91 & 2.58 \\
$\mathrm{LP}$ & Amarilis & $\mathrm{R}$ & $0.90 \mathrm{~b}$ & 0.61 & 1.22 \\
& Tomasa & $\mathrm{S}$ & $3.29 \mathrm{a}$ & 0.38 & 2.82 \\
& Yungay & MR & $3.27 \mathrm{a}$ & 0.37 & 2.80 \\
& Amarilis & $\mathrm{R}$ & $3.98 \mathrm{~b}$ & 0.53 & 3.41 \\
\hline
\end{tabular}

a Inoculated leaflets were incubated in petri plates moist chambers at $18^{\circ} \mathrm{C}$, weak light $\left(0.5 \mu \mathrm{E} \mathrm{m}^{-2} \mathrm{~s}^{-1}\right)$, and 14-h day photoperiod.

${ }^{\mathrm{b}}$ LGR, meters per day; SR, sporangia per square meter per day; LP, days.

${ }^{c}$ As reported by Franco (23). S = highly susceptible, MR = moderately resistant or tolerant, and $\mathrm{R}=$ resistant.

$\mathrm{d}$ Twelve observations (four isolates on three dates). Each observation was the mean of three subsamples (leaflets). Within each fitness component, means followed by the same letter are not significantly different according to the Tukey's test $(\alpha=0.05)$.

e Adjusted means represent the new model parameters for the host-pathogen interaction used in the LB2004 version of LATEBLIGHT. They were obtained as the quotient between the mean and the value obtained with the equation for the effect of temperature on the corresponding fitness component at $T=18^{\circ} \mathrm{C}(\mathrm{rLGR}=0.8844, \mathrm{rSR}=0.7357$, and $\mathrm{rLP}=1.1686)$ (Table 1).

TABLE 1. Polynomial equations used in the version of LATEBLIGHT developed by Doster et al. (15) (LB1990) and the version resulting from this study (LB2004) describing the effect of temperature on relative lesion growth rate (rLGR), relative sporulation rate (rSR), and relative latent period (rLP) ${ }^{\mathrm{a}}$

\begin{tabular}{|c|c|c|c|}
\hline Fitness component & Equation $^{\mathrm{b}}$ & Range $\left({ }^{\circ} \mathrm{C}\right)^{\mathrm{c}}$ & $R^{2}$ \\
\hline \multicolumn{4}{|l|}{ rLGR } \\
\hline LB1990 & $\left(0.00084+0.1261 \times \mathrm{T}-0.03079 \times \mathrm{T}^{2}+0.00308 \times \mathrm{T}^{3}-0.0001152 \times \mathrm{T}^{4}+0.000001414 \times \mathrm{T}^{5}\right)^{1 / 2}$ & $0 \leq \mathrm{T} \leq 35$ & \multirow{3}{*}{0.847} \\
\hline LB2004 & $0.126636-0.038378 \times \mathrm{T}+0.008593 \times \mathrm{T}^{2}-0.000229 \times \mathrm{T}^{3}$ & $8 \leq \mathrm{T} \leq 33$ & \\
\hline Extrapolation ${ }^{\mathrm{d}}$ & $-0.262690+0.064246 \times \mathrm{T}$ & $4 \leq \mathrm{T}<8$ & \\
\hline \multicolumn{4}{|l|}{ rSR } \\
\hline LB1990 & $-0.3882+0.2482 \times \mathrm{TH}-0.03817 \times \mathrm{TH}^{2}+0.00252 \times \mathrm{TH}^{3}-0.0000532 \times \mathrm{TH}^{4}$ & $0 \leq \mathrm{TH} \leq 26$ & \multirow{3}{*}{0.607} \\
\hline LB2004 & $-4.796667+1.021578 \times \mathrm{TH}-0.056437 \times \mathrm{TH}^{2}+0.000931 \times \mathrm{TH}^{3}$ & $7 \leq \mathrm{TH} \leq 25$ & \\
\hline \multicolumn{3}{|c|}{ 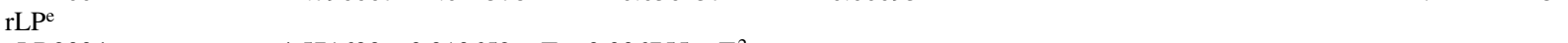 } & \\
\hline LB2004 & $4.571693-0.310652 \times \mathrm{T}+0.006755 \times \mathrm{T}^{2}$ & & 0.903 \\
\hline \multicolumn{4}{|c|}{ 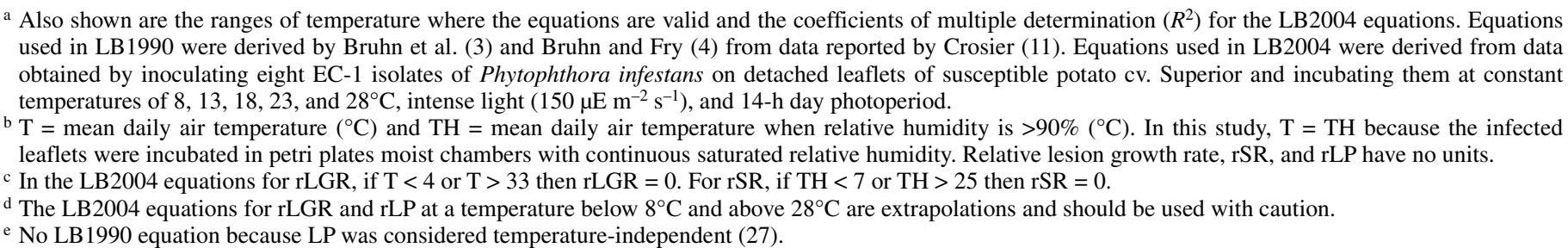 } \\
\hline
\end{tabular}



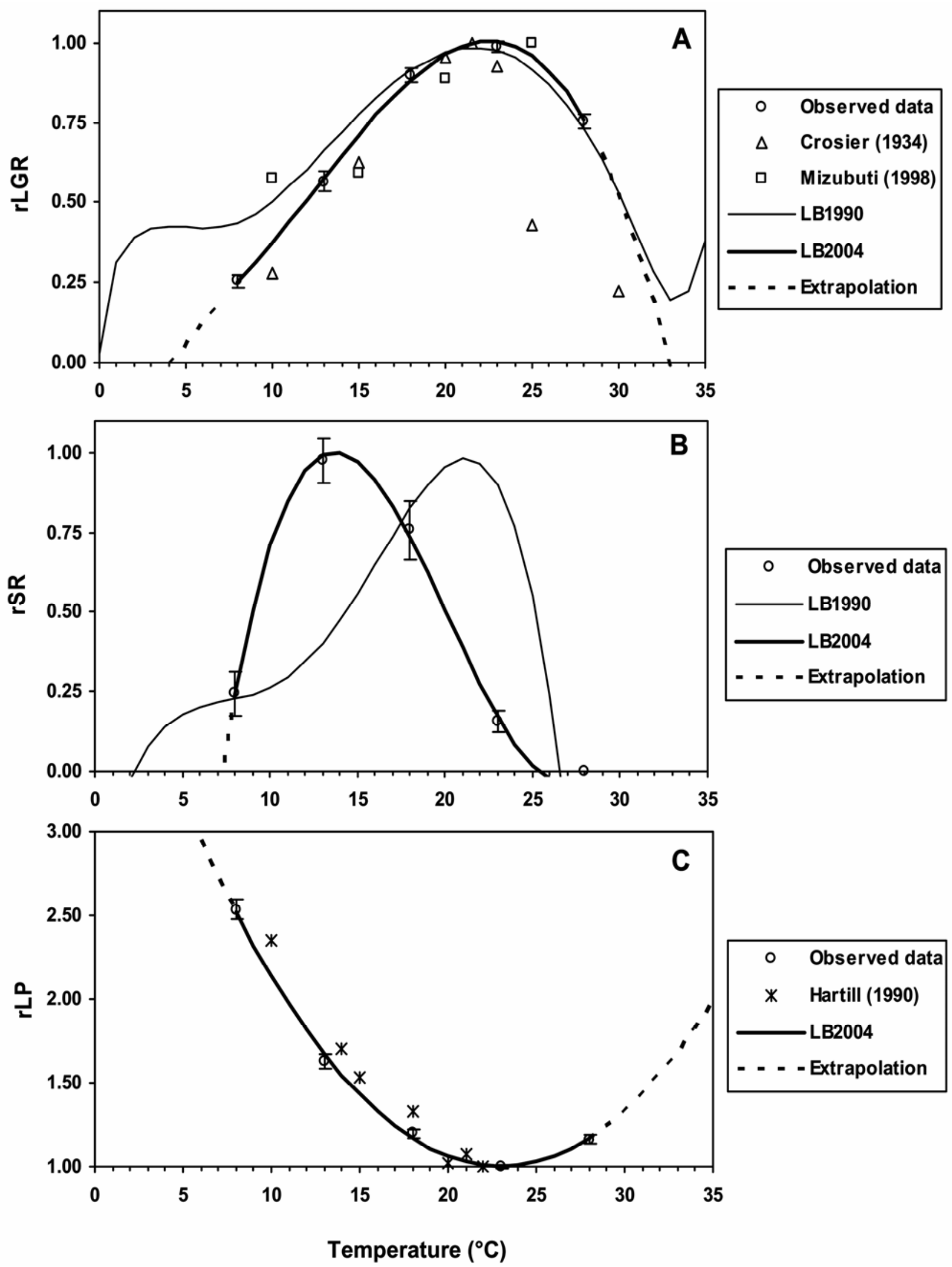

Fig. 1. Graphical representation of the polynomial equations used in the version of LATEBLIGHT developed by Doster et al. (15) (LB1990) and the version resulting from this study (LB2004) of A, relative lesion growth rate (rLGR), B, relative sporulation rate (rSR), and $\mathbf{C}$, relative latent period (rLP) as influenced by temperature. Relative values represent the effect of temperature on the fitness component. Predicted relative values equal to 1 indicate that the temperature is optimal for the fitness components. Thin lines represent the equations used in LB1990. Thick lines represent the equations used in LB2004. Dotted lines represent extrapolations of the equations used in LB2004. Empty circles represent the mean of 24 observations (eight EC-1 isolates of Phytophthora infestans inoculated on detached leaflets of the susceptible potato cv. Superior on three dates). Vertical bars represent the standard error of the mean. Also shown are data from Crosier (11) (empty triangles), Mizubuti and Fry (56) (empty squares), and Hartill et al. (37) (asterisks). 
(Fig. 1B). The LB1990 equation was bell-shaped with the optimal temperature at $21.2^{\circ} \mathrm{C}$, a sudden drop to zero at temperatures above the optimal, and a long left tail. The LB2004 equation was also bell-shaped, but with the optimal at $13.7^{\circ} \mathrm{C}$, a moderate drop to zero for temperatures below the optimal, and a moderately long tail for temperatures above the optimal.

The LB2004 equation for the effect of temperature on LP had the optimal (minimum) at $23.0^{\circ} \mathrm{C}$ (Fig. 1C). There was no LB1990 equation because LP was originally considered temperature-independent (4). Data from Hartill et al. (37) closely resembled our data (Fig. 1C).

Parameterization experiment. The interactions between cultivars and isolates were not statistically significant for LGR $(P=$ $0.773)$, SR $(P=0.586)$, and LP $(P=0.615)$. Therefore, the effects of isolates and cultivars on LGR, SR, and LP were investigated as additive. There were highly significant differences among isolates for SR and LP $(P<0.001)$, but no differences for LGR $(P=$ $0.779)$. Values of SR ranged from $1.04 \times 10^{8}$ sporangia $\mathrm{m}^{-2}$ day $^{-1}$ (isolate PCZ144) to $2.24 \times 10^{8}$ sporangia $\mathrm{m}^{-2}$ day $^{-1}$ (isolate PCZ108). Values of LP ranged from 3.18 days (isolate PCZ108) to 3.82 days (isolate PCZ144). The differences among cultivars were highly significant for LGR, SR, and LP $(P<0.010)$. Cv. Tomasa was the most susceptible, cv. Yungay intermediate, and cv. Amarilis the most resistant (Table 2). For SR and LP, cv. Yungay was as susceptible as cv. Tomasa, while for LGR, cv. Yungay was as resistant as cv. Amarilis. The reactions of these cultivars to $P$. infestans were consistent with those reported by Franco (23).

New model parameters of LGR, SR, and LP were obtained for the host-pathogen interaction (Table 2) after adjusting the values obtained in cvs. Tomasa, Yungay, and Amarilis to the optimal temperature using the equations reported in Table 1 . The new model parameters were between $3.40 \times 10^{-3}$ and $4.10 \times 10^{-3} \mathrm{~m}$ day $^{-1}$ for LGR, between $1.22 \times 10^{8}$ and $2.92 \times 10^{8}$ sporangia $\mathrm{m}^{-2}$ day $^{-1}$ for SR, and between 2.82 and 3.41 days for LP. These new parameters (estimated from experimental data) were lower than those used in LB1990 (estimated by calibration [15,27]) (data not shown). In the case of LGR and SR, this means slower predicted pathogen development on the plant, while in the case of LP it means the opposite.

Resulting version of LATEBLIGHT. The LB2004 version was obtained by (i) incorporating the LB2004 equations for the effect of temperature on LGR and SR; (ii) incorporating temperature-dependent LP; and (iii) replacing the host and pathogen parameters of LGR, SR, and LP by parameters for the hostpathogen interaction.

The calculation of LA was modified in order to accommodate the temperature-dependant LP, while the period of survival of the lesions remained fixed at 15 days, as in the original version of the model (4). Since LATEBLIGHT operates in a daily time step, the LP parameters would be rounded to the closest integer and, therefore, the significant differences found among cultivars (that may be fractions of a day) would not be considered by the model. For example, $\mathrm{LP}=2.80$ days for cv. Yungay (Table 2) would be treated the same as LP $=3.41$ days for cv. Amarilis. To avoid this limitation, sporulation was let to start when accumulated $\mathrm{rLP}^{-1}$ (ArLP) of a cohort of lesions was larger than truncated LP, i.e., 1 day or less before the end of LP. The simulated sporulating area (SSA) was adjusted for this early start of sporulation by multiplying the lesion area with a new variable, SSAfrac, calculated with equation 4 and having values between one and zero:

$$
\text { SSAfrac }=\text { LP }- \text { ArLP }
$$

A minor modification included in the LB2004 version was to eliminate the plant density and plot size variables. The plant density variable was used in LB1990 to express the density of initial inoculum as lesions per plant only. The plot size variable implied an effect of the plot size on the epidemic. However, since the biophysical mechanisms of dispersal of sporangia are not simulated (27), plot size can be eliminated. The LB2004 version is now a "point" model, i.e., without spatial extent, and with all spatial units expressed as square meters.

\section{DISCUSSION}

We modified and parameterized LATEBLIGHT for use in the Andes. The first modification was the incorporation of improved equations for the effect of temperature on LGR and SR.

There were important differences between the equations of the effect of temperature obtained in this study and the LB1990 equations for LGR and, particularly, for SR. Since the LB1990 equations were derived from data reported by Crosier (11), presumably using isolates of the old population of $P$. infestans, it is reasonable to speculate that these differences were due to a differential effect of temperature between the old and the new populations of $P$. infestans. However, we believe that this is not the case and that the differences between the LB1990 equations and the equations obtained in this study were due to errors in the calculation of the LB1990 equations. The first piece of evidence for this is the report of Mizubuti and Fry (56), who found no interaction between temperature and clonal lineages of the new and old populations of $P$. infestans for IP, LA, and SP. The second piece of evidence comes from the comparison between our data and those used to calculate the LB1990 equations. The equation for LGR was probably derived from data on progression of stem lesions (Fig. 11 in literature citation 11 [page 26]). We transformed the values provided by Crosier into proportions relative to the maximum and found that the resulting equation was more similar to the one in the present study than to the one in LB1990. A similar pattern was observed with data from Mizubuti and Fry (56), who used isolates of clonal lineages from the old and the new populations. However, their reported effect of temperature on LGR at $10^{\circ} \mathrm{C}$ was closer to that predicted by the LB1990 equation than that predicted by our equation (Fig. 1A). This may be an artifact of measuring IP (one of the variables used to estimate LGR in equation 1) with the naked eye (56) rather than using a dissecting microscope, as we did in our experiments. The drastic reduction of LGR at $25^{\circ} \mathrm{C}$ described by Crosier (11) looks like an erroneous outlier.

In the case of the LB1990 equation for SR, it is not clear how it was calculated in earlier work since only qualitative data were provided by Crosier (10). Data of Mizubuti and Fry (Fig. 3C in literature citation 56 [page 841]) on the effect of temperature on sporulation per unit of LA showed the optimal at $15^{\circ} \mathrm{C}$, which is close to what we found $\left(13.7^{\circ} \mathrm{C}\right)$. Thus, it seems that the effect of temperature on LGR and SR was not well described in the LB1990 version and that the effect of temperature on these fitness components is relatively constant across lineages of $P$. infestans.

The second modification to LATEBLIGHT was the incorporation of temperature-dependent LP. The effect of temperature on LP was similar to that reported in other studies. The data of Hartill et al. (37) closely resembled our data. The optimal temperature for LP according to these authors is $20.1^{\circ} \mathrm{C}$, while we determined that the optimal is $21.2^{\circ} \mathrm{C}$. Crosier (11) also found the optimal temperature for production of aerial mycelium on tubers to be approximately $21^{\circ} \mathrm{C}$. Because of the strong relationship between temperature and LP, this appears to be a very important modification of the model.

The third modification to LATEBLIGHT was to replace the host and pathogen parameters of LGR, SR, and LP by parameters for the host-pathogen interaction, which permitted the use of experimentally measured and, therefore, biologically meaningful values.

We found adjusted LP values of between 2.80 and 3.41 days. These values are within the range of 2.46 to 6.45 days that has 
been found in experiments conducted under controlled conditions with constant temperatures between 15 and $20^{\circ} \mathrm{C}(6,36,37,44)$. LPs ranging from 5 to 12 days have been found in experiments conducted under field conditions $(5,8)$. These differences in LP illustrate that fitness components cannot be compared across different experiments without at least adjusting for the effect of temperature. Our equations can be used for such an adjustment, and we suggest that future workers report both their adjusted and unadjusted values. The inclusion of control potato cultivars and $P$. infestans isolates allows for evaluating the degree to which data are comparable across experiments.

The adjusted LGR values found in this study were between $3.40 \times 10^{-3}$ and $4.10 \times 10^{-3} \mathrm{~m} \mathrm{day}^{-1}$, which are close to the values reported by other authors. For example, using data reported by Mizubuti and Fry (56), we calculated LGR for isolates of three clonal lineages of $P$. infestans infecting a highly susceptible potato cultivar incubated at constant temperatures of 15 and $20^{\circ} \mathrm{C}$. Mean LGR was $3.51 \times 10^{-3} \mathrm{~m} \mathrm{day}^{-1}$ for the US-1 lineage, $3.02 \times$ $10^{-3} \mathrm{~m} \mathrm{day}^{-1}$ for US-7, and $4.07 \times 10^{-3} \mathrm{~m} \mathrm{day}^{-1}$ for US-8. Colon et al. (7) reported mean LGR values of $4.01 \times 10^{-3}$ for a susceptible cultivar and $2.76 \times 10^{-3} \mathrm{~m} \mathrm{day}^{-1}$ for a partially resistant cultivar, both infected with a complex race of $P$. infestans incubated at 15 to $20^{\circ} \mathrm{C}$. As in the case of LP, low values of LGR found in other studies $(7,8,51)$ may be explained because LGR was measured under field conditions and, therefore, the temperature was not optimal.

The adjusted SR values we found were between $1.22 \times 10^{8}$ and $2.92 \times 10^{8}$ sporangia $\mathrm{m}^{-2}$ day $^{-1}$. Sporulation expressed as SR (sporangia per unit of area and time) is usually not reported in the literature. Most studies report sporulation as spore density (sporangia per unit of area), and it is not possible to transform it into SR because at least one of the other variables to estimate SR (IP, LP, and LA, according to equations 2 and 3 ) is not reported. To our knowledge, there are two studies in which spore density was evaluated daily and, therefore, this measure could be considered as SR. Lapwood (46) found values between $3.57 \times 10^{8}$ and $8.47 \times 10^{8}$ sporangia $\mathrm{m}^{-2}$ day $^{-1}$ under field conditions and presumably using an isolate of the old population of $P$. infestans. Colon et al. (7) found values between $1.00 \times 10^{8}$ and $1.80 \times 10^{9}$ sporangia $\mathrm{m}^{-2}$ day $^{-1}$ under controlled conditions using a complex race of $P$. infestans that probably belonged to the new populations. Metalaxyl-resistant isolates (such as the EC-1 isolates used in this study) have shown equal $(43)$ or lower $(12,16)$ sporulation in foliage than metalaxyl-sensitive isolates (such as most isolates of the old population [33]). Therefore, the moderately low values found in this study could be related to the use of metalaxylresistant isolates.

Raymundo et al. (67) suggested changing the time step of LATEBLIGHT from daily to hourly in order to accurately simulate the nonlinear effect of variation in temperature during the day. For example, according to Figure $1 \mathrm{~B}$, a mean daily temperature of $13.7^{\circ} \mathrm{C}$ is optimal for SR. Yet, temperature is not optimal during most of the day because of its daily cycle and, therefore, SR should be lower. The daily time step also limited differentiation of distinct latent periods. We solved the latter problem by starting sporulation 1 day before LP, but only on a fraction of tissue that is equal to the amount of time that otherwise would be lost by rounding LP to the closest integer. In a similar vein, it might be possible to use daily minimum and maximum temperature to more precisely estimate the effect of temperature on the various fitness components.

We did not convert the model to an hourly time step because (i) the modifications needed to do that were outside the scope of this study, and (ii) with the current time step (daily) the model has shown that it is able to accurately predict epidemics of potato late blight $(3,4,15,27)$. With the modifications to LP described here, we expect that LB2004 will perform at least as well as previously reported.
There are two important assumptions in the approach that we used to parameterize the interaction between a potato cultivar and a clonal lineage of $P$. infestans. The first assumption is that the measurements obtained under controlled conditions reflect the behavior of the plant and the pathogen under field conditions. This assumption is supported by data from Vleeshouwers et al. (83), although they found that detached leaves infected with the pathogen and incubated in moist chambers were more susceptible than infected leaves incubated in open trays or leaves on intact plants.

The second assumption is that the aggressiveness of the isolates used in the experiments is related to their multilocus genotype (clonal lineage), and that these isolates are a representative sample of those genotypes. There are conflicting results with respect to the link between aggressiveness and genotype. While several reports have showed this link $(44,55)$, others have not (6). In the case of a strong link between aggressiveness and genotype, the selection of isolates for the parameterization experiments could be done based on genotype, while in the absence of that link, the selection of isolates should be done based on aggressiveness. In any case, before the experiments the isolates should be screened to avoid those with unusually low or high aggressiveness (6). With respect to the degree of representativeness of the isolates, other authors who have investigated hypotheses about clonal lineages $(44,56)$ have used a similar number of isolates as a sample. However, we suggest that the number of isolates should be as large as possible in future parameterization experiments because of the presence of significant differences among isolates for SR and LP.

It is crucial to standardize the methodology to measure fitness components for future parameterization of the model and to allow for comparisons among experiments in general. There are many factors that could affect results in this type of experiment, e.g., the position of the leaf being inoculated (82). The methodology described in this study could be the starting point to standardize a protocol to measure fitness components to estimate parameters for LATEBLIGHT. In addition to other suggestions made above, we recommend the following. First, the spore concentration and drop volume should be investigated because there are indications that there is a positive correlation between spore concentration and LGR (Turkensteen, 1973 cited in Colon et al. [7]), and because with a large drop the initial radius of the lesion cannot be measured accurately. Recent studies have reduced the spore concentration to $0.3 \times 10^{4}$ sporangia $\mathrm{ml}^{-1}$ and the drop volume to $10 \mu \mathrm{l}$ (66). Second, the methodology used to estimate SR should be revised because there are indications that SR increases with time rather than being constant (66).

In this study, we adapted a plant disease model developed for temperate regions to one that could accommodate broader environmental and host conditions, such as those of the tropical highlands. A late blight forecast system was also recently adapted for tropical highland conditions $(34,35)$, and model adaptation to specific conditions seems to be a relatively common activity in plant models $(42,49,50,59)$, but to the best of our knowledge, this is one of the few examples of such adaptation in plant disease models. The strategy was to assure that major processes that are expected to respond to environmental variation are also modeled that way (as in the case of the equation for the effect of temperature on LP); to update functions with new data (as in the case of the equations for the effect of temperature on LGR and SR); and to use experimentally measured parameters rather than calibrated parameters (as in the case of those of the host-pathogen interaction).

Given the modifications described previously, the next logical step is to validate the model by comparing simulated with observed data. The validation of the LB2004 version of LATEBLIGHT for three locations from Peru is described by Andrade-Piedra et al. (1). 


\section{ACKNOWLEDGMENTS}

This work was supported by the International Potato Center (CIP), USAID 1998 Linkage Funds, and US-AID Project "Computer Simulation Models: A Tool for Transferring IPM Technologies from Developed to Developing Countries" (C15-073-TA-MOU-99). We thank W. Pérez, S. Gamboa, E. de la Torre, F. Ventura, and J. Paredes from CIP; and H. Mayton and C. Smart from Cornell University for technical support.

\section{LITERATURE CITED}

1. Andrade-Piedra, J. L., Hijmans, R. J., Juárez, H. S., Forbes, G. A., Shtienberg, D., and Fry, W. E. 2005. Simulation of potato late blight in the Andes. II: Validation of the LATEBLIGHT model. Phytopathology 95:1200-1208.

2. Antonovics, J., and Alexander, H. M. 1989. The concept of fitness in plant-fungal pathogen systems. Pages 185-214 in: Plant Disease Epidemiology, vol. 2. Genetics, Resistance, and Management. K. J. Leonard and W. E. Fry, eds. McGraw-Hill, New York.

3. Bruhn, J. A., Bruck, R. I., Fry, W. E., Arneson, P. A., and Keokosky, E. V. 1980. User's manual for LATEBLIGHT: A plant disease management game. Cornell Univ. Dept. Plant Pathol. Mimeo. 80-1.

4. Bruhn, J. A., and Fry, W. E. 1981. Analysis of potato late blight epidemiology by simulation modeling. Phytopathology 71:612-616.

5. Cañizares, C. A., and Forbes, G. A. 1995. Foliage resistance to Phytophthora infestans (Mont.) de Bary in the Ecuadorian national collection of Solanum phureja ssp. phureja Juz. \& Buk. Potato Res. 38:3-10.

6. Carlisle, D. J., Cooke, L. R., Watson, S., and Brown, A. E. 2002. Foliar aggressiveness of Northern Ireland isolates of Phytophthora infestans on detached leaflets of three potato cultivars. Plant Pathol. 51:424-434.

7. Colon, L. T., Budding, D. J., Keizer, L. C. P., and Pieters, M. M. J. 1995. Components of resistance to late blight (Phytophthora infestans) in eight South American Solanum species. Eur. J. Plant Pathol. 101:441-456.

8. Colon, L. T., Turkensteen, L. J., Prummel, W., Budding, D. J., and Hoogendoorn, J. 1995. Durable resistance to late blight (Phytophthora infestans) in old potato cultivars. Eur. J. Plant Pathol. 101:387-397.

9. Crissman, C. C., Espinosa, P., Ducrot, C. E. H., Cole, D. C., and Carpio, F. 1998. The case study site: Physical, health, and potato farming systems in Carchi province. Pages 85-120 in Economic, Environmental, and Health Tradeoffs in Agriculture: Pesticides and the Sustainability of Andean Potato Production. C. C. Crissman, J. M. Antle, and S. M. Capalbo, eds. Kluwer Academic Publishers and International Potato Center (CIP), Dordrecht, The Netherlands.

10. Crosier, W. 1932. Studies in the biology of Phytophthora infestans (Mont.) de Bary. Ph.D. thesis. Cornell University, Ithaca, NY.

11. Crosier, W. 1934. Studies in the biology of Phytophthora infestans (Mont.) de Bary. Cornell Univ. Agric. Exp. Stn. Mem. 155.

12. Day, J. P., and Shattock, R. C. 1997. Aggressiveness and other factors relating to displacement of populations of Phytophthora infestans in England and Wales. Eur. J. Plant Pathol. 103:379-391.

13. Devaux, A., and Haverkort, A. J. 1987. The effects of shifting planting dates and mulching on late blight (Phytophthora infestans) and drought stress of potato crops grown under tropical highland conditions. Exp. Agric. 23:325-333.

14. Doster, M. A., and Fry, W. E. 1991. Evaluation by computer simulation of strategies to time metalaxyl applications for improved control of potato late blight. Crop Prot. 10:209-214.

15. Doster, M. A., Milgroom, M. G., and Fry, W. E. 1990. Quantification of factors influencing potato late blight suppression and selection for metalaxyl resistance in Phytophthora infestans: A simulation approach. Phytopathology 80:1190-1198.

16. Dowley, L. J. 1987. Factors affecting the survival of metalaxyl-resistant strains of Phytophthora infestans (Mont.) de Bary in Ireland. Potato Res. 30:473-475.

17. Egúsquiza, R., and Apaza, W. 2001. Rancha of potato (Phytophthora infestans) in Peru-Country profile. Pages 27-37 in: Proc. Int. Workshop 'Complementing resistance to late blight (Phytophthora infestans) in the Andes'. E. N. Fernández-Northcote, ed. International Potato Center (CIP), Lima, Peru.

18. Fernández-Northcote, E. N., Navia, O., and Gandarillas, A. 2000. Basis of strategies for chemical control of potato late blight developed by PROINPA in Bolivia. Fitopatología 35:137-149.

19. Ferrandino, F. J. 1989. Spatial and temporal variation of a defoliating plant disease and reduction in yield. Agric. For. Meteorol. 47:273-289.

20. Fohner, G. R., Fry, W. E., and White, G. B. 1984. Computer simulation raises question about timing protectant fungicide application frequency according to a potato late blight forecast. Phytopathology 74:1145-1147.

21. Forbes, G. A., Escobar, X. C., Ayala, C. C., Revelo, J., Ordoñez, M. E., Fry, B. A., Doucett, K., and Fry, W. E. 1997. Population genetic structure of Phytophthora infestans in Ecuador. Phytopathology 87:375-380.

22. Forbes, G. A., and Jarvis, M. C. 1994. Host resistance for management of potato late blight. Pages 439-457 in: Advances in Potato Pests Biology and Management. G. W. Zehnder, M. L. Powelson, R. K. Jansson, and K. V. Raman, eds. The American Phytopathological Society, St. Paul, MN.

23. Franco, E. (ed.) 1994. Catálogo de Semilla Básica de Papa en el Perú, Proyecto de Apoyo a la Producción de Semilla e Investigación para Mejorar la Productividad de Papa en el Perú (SEINPA), Lima, Perú.

24. Fry, W. E. 1978. Quantification of general resistance of potato cultivars and fungicide effects for integrated control of potato late blight. Phytopathology 68:1650-1655.

25. Fry, W. E., Apple, A. E., and Bruhn, J. A. 1983. Evaluation of potato late blight forecasts modified to incorporate host resistance and fungicide weathering. Phytopathology 73:1054-1059.

26. Fry, W. E., Goodwin, S. B., Dyer, A. T., Matuszak, J. M., Drenth, A., Tooley, P. W., Sujkowski, L. S., Koh, Y. J., Cohen, B. A., Spielman, L. J., Deahl, K. L., Inglis, D. A., and Sandlan, K. P. 1993. Historical and recent migrations of Phytophthora infestans: Chronology, pathways, and implications. Plant Dis. 77:653-661.

27. Fry, W. E., Milgroom, M. G., Doster, M. A., Bruhn, J. A., and Bruck, R. I. 1991. LATEBLIGHT: A plant disease management game-User's Manual. Version 3.1. Microsoft Windows adaptation by B. E. Ticknor and P. A. Arneson. Cornell Univ. Dept. Plant Pathol., Ithaca, NY.

28. Fry, W. E., Thurston, H. D., and Stevenson, W. R. 2001. Late blight. Pages 28-30 in: Compendium of Potato Diseases. 2nd. ed. W. R. Stevenson, R. Loria, G. D. Franc, and D. P. Weingartner, eds. The American Phytopathological Society, St. Paul, MN.

29. Gees, R., and Hohl, H. R. 1988. Cytological comparison of specific (R3) and general resistance to late blight in potato leaf tissue. Phytopathology 78:350-357

30. Goodwin, S. B., Cohen, B. A., Deahl, K. L., and Fry, W. E. 1994. Migration from northern Mexico as the probable cause of recent genetic changes in populations of Phytophthora infestans in the United States and Canada. Phytopathology 84:553-558.

31. Goodwin, S. B., Cohen, B. A., and Fry, W. E. 1994. Panglobal distribution of a single clonal lineage of the Irish potato famine fungus. Proc. Natl. Acad. Sci. USA 91:11591-11595.

32. Goodwin, S. B., Drenth, A., and Fry, W. E. 1992. Cloning and genetic analyses of two highly polymorphic, moderately repetitive nuclear DNAs from Phytophthora infestans. Curr. Genet. 22:107-115.

33. Goodwin, S. B., Sujkowski, L. S., and Fry, W. E. 1996. Widespread distribution and probable origin of resistance to metalaxyl in clonal genotypes of Phytophthora infestans in the United States and western Canada. Phytopathology 86:793-800.

34. Grünwald, N. J., Romero Montes, G., Lozoya Saldaña, H., Rubio Covarrubias, O. A., and Fry, W. E. 2002. Potato late blight management in the Toluca valley: Field validation of SimCast modified for cultivars with high field resistance. Plant Dis. 86:1163-1168.

35. Grünwald, N. J., Rubio-Covarrubias, O. A., and Fry, W. E. 2000. Potato late-blight management in the Toluca Valley: Forecasts and resistant cultivars. Plant Dis. 84:410-416.

36. Guzmán-N, J. 1964. Nature of partial resistance of certain clones of three Solanum species to Phytophthora infestans. Phytopathology 54:13981404.

37. Hartill, W. F. T., Young, K., Allan, D. J., and Henshall, W. R. 1990. Effects of temperature and leaf wetness on the potato late blight. N. Z. J. Crop Hortic. Sci. 18:181-184.

38. Haverkort, A. J. 1990. Ecology of potato cropping systems in relation to latitude and altitude. Agric. Syst. 32:251-272.

39. Haverkort, A. J., and Bicamumpaka, M. 1986. Correlation between intercepted radiation and yield of potato crops infested by Phytophthora infestans in central Africa. Neth. J. Plant Pathol. 92:239-247.

40. Hijmans, R. J. 2001. Global distribution of the potato crop. Am. J. Potato Res. 78:403-412.

41. Hijmans, R. J., Forbes, G. A., and Walker, T. S. 2000. Estimating the global severity of potato late blight with GIS-linked disease forecast models. Plant Pathol. 49:697-705.

42. Jagtap, S. S., and Jones, J. W. 2002. Adaptation and evaluation of the CROPGRO-soybean model to predict regional yield and production. Agric. Ecosyst. Environ. 93:73-85.

43. Kadish, D., Grinberger, M., and Cohen, Y. 1990. Fitness of metalaxylsensitive and metalaxyl-resistant isolates of Phytophthora infestans on susceptible and resistant potato cultivars. Phytopathology 80:200-205.

44. Kato, M., Mizubuti, E. S., Goodwin, S. B., and Fry, W. E. 1997. Sensitivity to protectant fungicides and pathogenic fitness of clonal lineages of Phytophthora infestans in the United States. Phytopathology 87:973-978.

45. Kuehl, R. O. 2000. Design of Experiments: Statistical Principles of Research Design and Analysis. 2nd ed. Duxbury Press, Pacific Grove, CA. 
46. Lapwood, D. H. 1961. Potato haulm resistance to Phytophthora infestans. II. Lesion production and sporulation. Ann. Appl. Biol. 49:316-330.

47. Legard, D. E., Lee, T. Y., and Fry, W. E. 1995. Pathogenic specialization in Phytophthora infestans: Aggressiveness on tomato. Phytopathology 85:1356-1361.

48. Levy, Y., Cohen, Y., and Benderly, M. 1991. Disease development and buildup of resistance to oxadixyl in potato crops inoculated with Phytophthora infestans as affected by oxadixyl and oxadixyl mixtures: Experimental and simulation studies. J. Phytopathol. 132:219-229.

49. Lyamchai, C. J., Gillespie, T. J., and Brown, D. M. 1997. Estimating maize yield in northern Tanzania by adapting SIMCOY, a temperate-zone simulation model. Agric. For. Meteorol. 85:75-86.

50. Manschadi, A. M., Sauerborn, J., Stutzel, H., Gobel, W., and Saxena, M. C. 1998. Simulation of faba bean (Vicia faba L.) growth and development under Mediterranean conditions: Model adaptation and evaluation. Eur. J. Agron. 9:273-293.

51. Mayton, H., Forbes, G. A., Mizubuti, E. S. G., and Fry, W. E. 2001. The roles of three fungicides in the epidemiology of potato late blight. Plant Dis. 85:1006-1012.

52. Michaelides, S. C. 1985. A simulation model of the fungus Phytophthora infestans (Mont.) de Bary. Ecol. Model. 28:121-137.

53. Michaelides, S. C. 1991. A dynamic model of the interactions between the potato crop and Phytophthora infestans. EPPO Bull. 21:515-525.

54. Milgroom, M. G., and Fry, W. E. 1988. A simulation analysis of the epidemiological principles for fungicide resistance management in pathogen populations. Phytopathology 78:565-570.

55. Miller, J. S., Johnson, D. A., and Hamm, P. B. 1998. Aggressiveness of isolates of Phytophthora infestans from the Columbia Basin of Washington and Oregon. Phytopathology 88:190-197.

56. Mizubuti, E. S. G., and Fry, W. E. 1998. Temperature effects on developmental stages of isolates from three clonal lineages of Phytophthora infestans. Phytopathology 88:837-843.

57. Navia, O., Torrez, R., Trujllo, A., Fernández-Northcote, E. N., Gandarillas, A., and Gabriel, J. 2001. Tizon of potato (Phytophthora infestans) in Bolivia-Country profile. Pages 1-10 in: Proc. Int. Workshop 'Complementing resistance to late blight (Phytophthora infestans) in the Andes'. E. N. Fernández-Northcote, ed. International Potato Center (CIP), Lima, Peru.

58. Nelson, R., Mundt, C., Orrego, R., Ortiz, O., Fredrix, M., Tenorio, J., and Vien, N. V. 2001. Working with resource-poor farmers to manage plant diseases. Plant Dis. 85:684-695.

59. Nemecek, T., Derron, J. O., Roth, O., and Fischlin, A. 1996. Adaptation of a crop-growth model and its extension by a tuber size function for use in a seed potato forecasting system. Agric. Syst. 52:419-437.

60. Neter, J., Kutner, M. H., Nachtsheim, C. J., and Wasserman, W. 1996. Applied Linear Statistical Models. 4th ed. WCB McGraw-Hill, Boston, MA.

61. Ortiz, O., Garrett, K. A., Heath, J. J., Orrego, R., and Nelson, R. J. 2004. Management of potato late blight in the Peruvian highlands: Evaluating the benefits of farmer field schools and farmer participatory research. Plant Dis. 88:565-571.

62. Oyarzún, P. J., Taipe, J. A., and Forbes, G. A. 2001. Phytophthora infestans characteristics and activity in Ecuador-Country profile. Pages 15-25 in: Proc. Int. Workshop "Complementing resistance to late blight (Phytophthora infestans) in the Andes". E. N. Fernández-Northcote, ed. International Potato Center (CIP), Lima, Peru.

63. Parlevliet, J. E. 1979. Components of resistance that reduce the rate of epidemic development. Annu. Rev. Phytopathol. 17:203-222.

64. Pérez, W. G., Gamboa, J. S., Falcón, Y. V., Coca, M., Raymundo, R. M., and Nelson, R. J. 2001. Genetic structure of Peruvian populations of Phytophthora infestans. Phytopathology 91:956-965.

65. Raposo, R., Wilks, D. S., and Fry, W. E. 1993. Evaluation of potato late blight forecasts modified to include weather forecasts: A simulation analysis. Phytopathology 83:103-108.

66. Raymundo, R. M. 2004. Esporulación de Phytophthora infestans en el cultivo de papa (Solanum tuberosum) y su relación con el área de lesión. M.S. thesis. Universidad Nacional Agraria La Molina, Lima, Perú.
67. Raymundo, R. M., Andrade-Piedra, J. L., Juárez, H. S., Forbes, G. A., and Hijmans, R. J. 2002. Towards an integrated and universal cropdisease model for potato late blight. Pages 77-82 in: Proc. Global Initiative on Late Blight (GILB) Conference "Late blight: Managing the global threat". C. Lizárraga, ed. International Potato Center (CIP), Lima, Peru.

68. Rykiel, E. J. 1996. Testing ecological models: The meaning of validation. Ecol. Model. 90:229-244.

69. Schrödter, H., and Ullrich, J. 1967. A mathematical-statistical solution of the problem of forecasting epidemics by means of meteorological parameters, presented from the example of potato late blight (Phytophthora infestans). Agric. Meteorol. 4:119-135 (in German).

70. Shtienberg, D., Doster, M. A., Pelletier, J. R., and Fry, W. E. 1989. Use of simulation models to develop a low-risk strategy to suppress early and late blight in potato foliage. Phytopathology 79:590-595.

71. Shtienberg, D., and Fry, W. E. 1990. Field and computer simulation evaluation of spray-scheduling methods for control of early and late blight of potato. Phytopathology 80:772-777.

72. Shtienberg, D., and Fry, W. E. 1990. Quantitative analysis of host resistance, fungicide and weather effects on potato early and late blight using computer simulation models. Am. Potato J. 67:277-286.

73. Shtienberg, D., Raposo, R., Bergeron, S. N., Legard, D. E., Dyer, A. T. and Fry, W. E. 1994. Incorporation of cultivar resistance in a reducedsprays strategy to suppress early and late blights on potato. Plant Dis. 78:23-26.

74. Spadafora, V. J., Bruhn, J. A., and Fry, W. E. 1984. Influence of selected protectant fungicides and host resistance on simple and complex potato late blight forecasts. Phytopathology 74:519-523.

75. Spielman, L. J., Drenth, A., Davidse, L. C., Sujkowski, L. J., Gu, W. Tooley, P. W., and Fry, W. E. 1991. A second world-wide migration and population displacement of Phytophthora infestans? Plant Pathol. 40: $422-430$

76. Spielman, L. J., Sweigard, J. A., Shattock, R. C., and Fry, W. E. 1990. The genetics of Phytophthora infestans: Segregation of allozyme markers in F2 and backcross progeny and the inheritance of virulence against potato resistance genes $R 2$ and $R 4$ in F1 progeny. Exp. Mycol. 14:57-69.

77. Stephan, S., and Gutsche, V. 1980. An algorithmic model to simulate Phytophthora epidemics (SIMPHYT). Arch. Phytopathol. Pflanzenschutz 16:183-191 (in German).

78. Therrien, C. D., Tooley, P. W., Spielman, L. J., Fry, W. E., Ritch, D. L., and Shelly, S. E. 1993. Nuclear DNA content, allozyme phenotypes and metalaxyl sensitivity of Phytophthora infestans from Japan. Mycol. Res. 97:945-950.

79. Tooley, P. W., Sweigard, J. A., and Fry, W. E. 1986. Fitness and virulence of Phytophthora infestans isolates from sexual and asexual populations. Phytopathology 76:1209-1212.

80. van Haren, R. J. F., and Jansen, D. M. 1999. LINBAL, light interception by active layers-Description and application of a water, nitrogen and late blight limited potato growth model for the Andean ecoregion. Plant Research International, Wageningen, The Netherlands. Note 16.

81. van Oijen, M. 1989. On the use of mathematical models from human epidemiology in breeding for resistance to polycyclic fungal leaf diseases of crops. Pages 26-37 in: Parental Line Breeding and Selection in Potato Breeding. K. M. Louwes, H. A. J. M. Toussaint, and L. M. W. Dellaert, compilers. Pudoc, Wageningen, The Netherlands.

82. Visker, M. H. P. W., Keizer, L. C. P., Budding, D. J., Van Loon, L. C., Colon, L. T., and Struik, P. C. 2003. Leaf position prevails over plant age and leaf age in reflecting resistance to late blight in potato. Phytopathology 93:666-674.

83. Vleeshouwers, V. G. A. A., van Dooijeweert, W., Keizer, L. C. P., Sijpkes, L., Govers, F., and Colon, L. T. 1999. A laboratory assay for Phytophthora infestans resistance in various Solanum species reflects the field situation. Eur. J. Plant Pathol. 105:241-250.

84. Walker, T. S., Schmiediche, P. E., and Hijmans, R. J. 1999. World trends and patterns in the potato crop: An economic and geographic survey. Potato Res. 42:241-264 